\title{
Assessment of self-perception of physical fitness and proposal for standards among Chilean adolescent students: the EAPAF study
}

\author{
Marco Cossio-Bolaños, M.D. ${ }^{a, b, c}$, Pablo Vasquez, B.S. ${ }^{d}$, Cristian Luarte-Rocha, Magister ${ }^{b, e}$, \\ José Sulla-Torres Magisterf and Rossana Gómez Campos, M.D.b,c,d,g
}

\begin{abstract}
Introduction: Physical fitness may be assessed among children and adolescents in a quantitative and qualitative manner. At present, in Chile, there are no tools available to assess self-perception of physical fitness. Therefore, the purpose of this study was to develop a valid and reliable instrument that would allow to assess selfperception of physical fitness among adolescents and propose standards for age and sex.

Material and methods: Asurvey wasadministered among adolescent students from six public schools in the Maule Region, Chile, selected in a probabilistic (stratified) fashion. To measure self-perception of physical fitness, a qualitative instrument was developed: the Self-Perception of Physical Fitness Scale (EAPAF, escala de autopercepción de la aptitud física), which is made up of four dimensions and 18 questions. The LMS method (L: Box-Cox coefficient, M: median curve, and S: variation coefficient) was used to establish percentiles and propose references by dimension, age and sex.
\end{abstract}

Results: A total of 3060 adolescents (1702 boys and 1358 girls) aged 11.0 to 18.9 years old were included. The factor analysis evidenced four factors. Saturation values were above 0.40 . The percentage of instrument explanation reached $54.24 \%$. In terms of reliability, the 18 questions reflected that Cronbach's alpha was between 0.82 and 0.85 . Percentiles (p15, p50 and p85) were developed to classify self-perception of physical fitness by dimension, age and sex. Boys showed higher scores in the self-perception of physical fitness scale when compared to girls $(p<0.001)$. Conclusion: The instrument developed in this study was valid and reliable. In addition, the standards proposed may become a useful tool to classify adolescents in relation to their selfperception of physical fitness.

Key words: physical fitness, reliability and validity, self-perception, adolescent.

http:/ /dx.doi.org/10.5546/aap.2016.eng.319

Rossana Gómez

Campos, M.D.

rossaunicamp@

gmail.com

\section{Funding:}

Regular Fondecyt

Project 1141295.

Conflict of interest: None.

Received: 10-2-2015

Accepted: 1-15-2016 refers to a wide range of physiological and psychological features. ${ }^{2}$ This allows to establish a baseline for the development of physical fitness among athletic individuals and the maintenance of acceptable health levels among non-athletic persons.

Historically, physical fitness has been defined as having three components: muscle strength and endurance, cardiorespiratory endurance and motor ability. ${ }^{3}$ However, at present, a fourth component has been taken into consideration: a morphological factor, which is directly related to body composition.

In general, physical fitness has demonstrated to be a major marker of health among children and adolescents. ${ }^{2}$ The assessment of physical fitness in student populations acquires a fundamental significance for professionals working in the clinical, education and public health sectors. In fact, in the school setting, the method that has been adopted to measure physical fitness, regardless of the dimension (health and sports performance), has always been focused on the objective assessment by means of physical tests. ${ }^{5,6}$ However, the qualitative (subjective) method, such as the survey (self-reporting) technique, has been scarcely used, although recent studies have demonstrated its usefulness as a predictor of risk for cardiovascular disease ${ }^{7,8}$ and may be easily implemented in the school setting. ${ }^{8}$ In addition, it is a practical method to gather a wide range of data.

In this regard, the Education Quality Measurement System of the Ministry of Education of Chile has issued guidelines for assessing physical 
fitness among adolescent Chilean students, ${ }^{9}$ which provide a battery to diagnose physical fitness among students attending the $8^{\text {th }}$ grade of basic education (approximately 14 to 18 years old).

Basically, this perspective follows a quantitative approach and is restricted to a specific adolescent age group; in addition, it lacks specific reference standards for the Chilean population. Such disadvantages hinder the possibility of making an accurate, fast and simultaneous assessment in large population groups, so it is necessary to develop effective field-based (qualitative) tests that allow to assess self-perception of physical fitness among adolescents, require low-cost equipment and can be used to test more than one person at a time..$^{10}$ These tests should also meet validity and reliability requirements.

Therefore, the objective of this study was to develop a valid and reliable instrument to assess self-perception of physical fitness among adolescent Chilean students and propose standards for age and sex.

\section{METHODS}

A cross-sectional, descriptive study was conducted at six public (municipal) schools of the Maule Region, Chile. In general, in Chile, children attending municipal schools belong to a middle socioeconomic status.

The sample was selected on a probabilistic fashion (stratification with proportional allocation), where the number of sample elements was directly proportional to the stratum size within the population, considering age and sex.

\section{Inclusion criteria}

The study included adolescents whose parents had signed an informed consent were present on the assessment day and gave their assent, and who gave their own consent if older than 18 years old. Parents and legal tutors had been informed, in advance, on the administration of the questionnaire to assess their children's selfperception of physical fitness. The study was entirely approved by each school administration and the Ethics Committee of Universidad Autónoma de Chile.

\section{Procedures}

The technique used to measure the selfperception of physical fitness outcome measure was a survey. All data were recorded in a questionnaire, which was divided into two sections (demographic data and outcome measure components).

Data collection took place from May through August 2015. Questionnaires were administered during Physical Education classes (8:00 a.m.12:00 p.m.). Participants had 10-15 minutes to answer the questionnaire. The procedure was conducted by four Physical Education teachers, who were duly trained and experienced in surveytaking methods.

Decimal age was established by recording the result of subtracting the date of the assessment (day, month, year) from the day, month and year of birth. The questionnaire was self-administered by adolescents in their classroom. The four survey takers described the study objective and answered all questions regarding the questionnaire content.

FIGURE 1. Operationalization of the outcome measure self-perception of physical fitness among adolescents

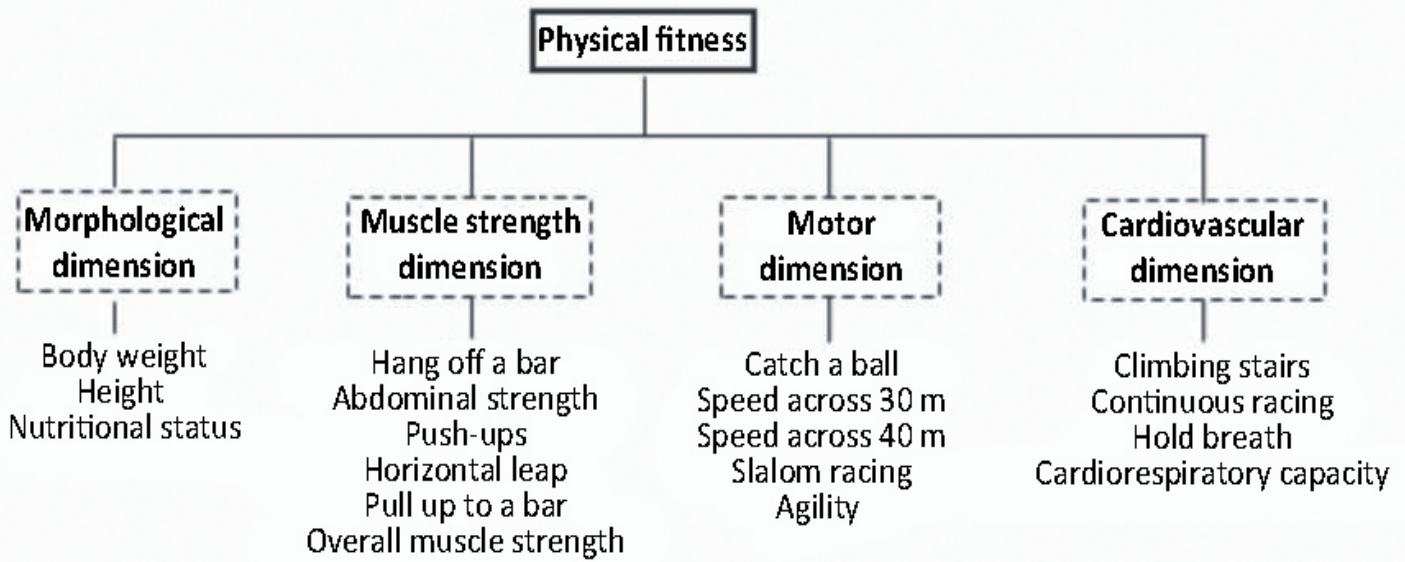




\section{Instrument development}

The self-perception of physical fitness scale (EAPAF, escala de autopercepción de la aptitud física) was developed based on content validity (see Annex). Operationalization was applied to the physical fitness outcome measure using four dimensions: morphological, muscle strength, motor and cardiovascular. Each dimension was the basis for a set of questions used to measure the EAPAF properties and features (Figure 1). Answers were categorized into a Likert-type scale. Options were: a) strongly agree, b) neither agree nor disagree, and c) strongly disagree.

\section{Instrument validation and reliability}

The EAPAF was validated using the construct method. The confirmatory factor analysis technique was implemented. Following rotation, results were converged into four factors (dimensions), as proposed initially. Reliability was established using an internal consistency analysis.

\section{Cut-off points}

Cut-off points were established based on percentiles by age and sex: $\mathrm{p}<15$ indicated a low self-perception of physical fitness; $p \geq 15-p$ 85, a moderate self-perception; and $p>85$, a high selfperception.

\section{Statistical analysis}

Data normalization was verified using the Kolmogorov-Smirnov test. Descriptive statistics was used to analyze frequencies, percentages, averages $(X)$ and standard deviations. Percentile distribution was established using the LMS method $^{11}$ for the $15^{\text {th }}, 50^{\text {th }}$ and $85^{\text {th }}$ percentiles. Data were normalized in advance for each age group and sex. A Box-Cox power transformation was performed. The maximum penalized likelihood estimation was implemented to develop three smoothed curves: L(t) Box-Cox Power, M(t) median and $S(t)$ variation coefficient. Percentiles were constructed for each component and the overall EAPAF according to the mathematical model proposed by Cole et al. ${ }^{11}$ The LMS Chart Maker Pro software version 2.3 was used to this end. Instrument validity was established using a multivariate analysis. The extraction of principal components technique, Varimax rotation, KaiserMeyer-Olkin (KMO) measure, eigenvalues and variance percentage were applied. Cronbach's alpha was used for reliability. Differences between sexes were obtained using the $t$ test for independent samples. A value of $p<0.001$ was used in all cases. Results were processed and analyzed first using Excel spreadsheets and then, the SPSS 18.0 software.

\section{RESULTS}

Out of 19870 subjects, 3060 adolescents (1702 boys and 1358 girls) completed the survey. They accounted for $15.4 \%$ of the target population, considering a $5 \%$ precision and a $95 \%$ confidence interval (CI).

Their age ranged from 11.0 to 18.9 years old.

Table 1 describes the frequency of sport activity at and outside school and smoking habits.

Validity and reliability values are described in Table 2.

The factor analysis evidenced four factors out of 18 interactions. The four dimensions of physical fitness evidenced saturation values above 0.40 . Three questions were grouped under the morphological dimension, six under the muscle strength dimension, five under the motor dimension, and four under the cardiovascular dimension. The percentage of instrument explanation reached $54.24 \%$. In terms of reliability, the 18 questions reflected a Cronbach's alpha

TABLE 1. Sport activity and smoking habit $(n=360)$

\begin{tabular}{|c|c|c|c|}
\hline & Frequency & Boys $(n=1702)$ & Girls $(n=1358)$ \\
\hline \multirow[t]{3}{*}{ Sport activity at school } & Always & $638(37.5 \%)$ & 509 (37.5\%) \\
\hline & Sometimes & $531(31.5 \%)$ & $424(31.2 \%)$ \\
\hline & Never & $533(31.0 \%)$ & $425(31.5 \%)$ \\
\hline \multirow[t]{3}{*}{ Sport activity outside school } & Always & $558(32.8 \%)$ & $459(33.8 \%)$ \\
\hline & Sometimes & $491(28.8 \%)$ & $394(29.0 \%)$ \\
\hline & Never & $653(38.4 \%)$ & $505(37.2 \%)$ \\
\hline \multirow[t]{3}{*}{ Smoking habit } & Always & $532(31.3 \%)$ & $425(31.3 \%)$ \\
\hline & Sometimes & $658(38.7 \%)$ & $424(31.2 \%)$ \\
\hline & Never & $512(30.0 \%)$ & $509(37.5 \%)$ \\
\hline
\end{tabular}


between 0.82 and 0.85 . In general, the EAPAF demonstrated a high level of internal consistency (0.84), as described in Table 2.

Each EAPAF dimension separately and all dimensions combined were distributed into the $15^{\text {th }}, 50^{\text {th }}$ and $85^{\text {th }}$ percentiles by age and sex.

Table 3 shows smoothed values obtained using the LMS method.

The four EAPAF dimensions were plotted into the $15^{\text {th }}, 50^{\text {th }}$ and $85^{\text {th }}$ percentiles by age and sex. These results are shown in Figure 2. Values in the morphological dimension were relatively similar across all age groups and between both sexes. Girls showed a mild reduction over time in the muscle strength, motor and cardiovascular dimensions. On the contrary, among boys, values remained relatively stable.

Table 3 shows comparisons of average and \pm SD values by dimension and the overall EAPAF. No significant differences were observed in the morphological dimension; however, girls had lower values in the muscle strength, motor and cardiovascular dimensions of the EAPAF when compared to boys. In general, boys had a greater self-perception of physical fitness than girls $(p<0.001)$.

TABLE 2. Confirmatory analysis and Cronbach's alpha for validity and reliability of the instrument developed in this study

\begin{tabular}{lll}
\hline$N^{\circ}$ & Dimensions / items & FA Cronbach's alpha
\end{tabular}

Morphological dimension

1. In general, my weight is within normal ranges for my age and sex.

0.476

0.83

2. Often, during the development stage, my height is within normal ranges for my age and sex.

0.592

3. In general, based on my present nutritional status, I think I belong to the following nutritional status category:

Eigenvalues

$\%$ of explained variance

Muscle strength dimension

4. I can usually hang off a bar for 10 seconds or more.

5. In general, I like doing abs.

6. I feel I can easily do push-ups, at least 5 push-ups.

7. I often easily leap over an obstacle (one-foot takeoff to a landing on the other foot), either while walking or jogging.

8. I can pull myself up to the bar (hang from the bar) several times.

9. Level of muscle strength for my age and sex:

Eigenvalues

$\%$ of explained variance

\section{Motor dimension}

10. I often quickly and easily catch a ball with both hands.

11. In general, I can run at top speed more than 30 meters in a straight line.

12. Given my present physical characteristics, I can run 4 meters at top speed (back and forth more than 6 times).

13. I can easily run and leap over obstacles on a straight line (without knocking down the obstacles)

14. Level of agility for my age and sex:

Eigenvalues

$\%$ of explained variance

Cardiovascular dimension

15. I can walk up six flights of stairs without stopping.

16. I can easily jog for more than 15 minutes continuously and without stopping.

17. I can frequently hold my breath for at least 30 seconds.

18. General consideration of my cardiorespiratory fitness:

Eigenvalues

$\%$ of explained variance

Cronbach's alpha
0.554

1.4

8.34

0.632

0.549

0.612

0.634

0.664

0.568

3.1

18.2

0.537

0.689

0.693

0.641

0.635

2.7

15.2

0.483

0.571

0.461

0.541

1.6

12.5

--
0.85

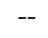

FA: factor analysis (saturations). 


\section{DISCUSSION}

The proposed scale allows to assess selfperception of physical fitness among Chilean adolescent boys and girls aged 11.0-18.9 years old. The scale was developed on the basis of previous studies that described the content and structure of physical fitness domains. ${ }^{12,13}$ Actually, the EAPAF covers four domains (morphological, muscle strength, motor and cardiovascular) that measure physical fitness based on 18 items.

This process is called outcome measure operationalization and is supported by the theoretical correspondence between construct and data. ${ }^{14}$ Recommendations made by Pettee et al. ${ }^{15}$ were followed, which describe the adoption of a conceptual framework domain to adequately

TABLE 3. Smoothed percentile distribution for the self-perception of physical fitness scale by dimension, age and sex

\begin{tabular}{|c|c|c|c|c|c|c|c|c|c|c|c|c|c|c|}
\hline $\begin{array}{l}\text { Age groups } \\
\text { (years) }\end{array}$ & $\mathbf{L}$ & $\mathbf{M}$ & $\mathrm{S}$ & $\begin{array}{l}\text { Girls } \\
\text { n }\end{array}$ & P 15 & P 50 & P 85 & $\mathbf{L}$ & $\mathbf{M}$ & $\mathrm{S}$ & $\begin{array}{c}\text { Boys } \\
\mathrm{n}\end{array}$ & P 15 & P 50 & P 85 \\
\hline \multicolumn{15}{|c|}{ Morphological dimension } \\
\hline 11.0-11.9 & 2.8 & 7.1 & 0.2 & 82 & 5.7 & 7.1 & 8.1 & 2.7 & 7.0 & 0.2 & 95 & 5.7 & 7.0 & 8.0 \\
\hline $12.0-12.9$ & 2.7 & 7.0 & 0.2 & 185 & 5.6 & 7.0 & 8.0 & 2.6 & 7.1 & 0.2 & 152 & 5.7 & 7.1 & 8.1 \\
\hline 13.0-13.9 & 2.5 & 6.9 & 0.2 & 117 & 5.5 & 6.9 & 8.0 & 2.5 & 7.1 & 0.2 & 200 & 5.6 & 7.1 & 8.1 \\
\hline $14.0-14.9$ & 2.4 & 6.9 & 0.2 & 264 & 5.4 & 6.9 & 8.0 & 2.4 & 7.0 & 0.2 & 275 & 5.6 & 7.0 & 8.2 \\
\hline $15.0-15.9$ & 2.3 & 6.9 & 0.2 & 202 & 5.4 & 6.9 & 8.1 & 2.3 & 7.0 & 0.2 & 208 & 5.5 & 7.0 & 8.1 \\
\hline $16.0-16.9$ & 2.2 & 6.9 & 0.2 & 187 & 5.4 & 6.9 & 8.1 & 2.2 & 6.9 & 0.2 & 264 & 5.4 & 6.9 & 8.1 \\
\hline 17.0-17.9 & 2.1 & 6.8 & 0.2 & 241 & 5.3 & 6.8 & 8.1 & 2.2 & 6.9 & 0.2 & 352 & 5.3 & 6.9 & 8.1 \\
\hline 18.0-18.9 & 1.9 & 6.8 & 0.2 & 80 & 5.2 & 6.8 & 8.1 & 2.2 & 6.9 & 0.2 & 156 & 5.4 & 6.9 & 8.2 \\
\hline \multicolumn{15}{|c|}{ Muscle strength dimension } \\
\hline $11.0-11.9$ & 1.7 & 14.2 & 0.2 & 82 & 11.3 & 14.2 & 16.7 & 2.5 & 14.9 & 0.2 & 95 & 11.8 & 14.9 & 17.2 \\
\hline $12.0-12.9$ & 1.6 & 13.9 & 0.2 & 185 & 11.0 & 13.9 & 16.5 & 2.5 & 15.0 & 0.2 & 152 & 11.9 & 15.0 & 17.3 \\
\hline $13.0-13.9$ & 1.6 & 13.6 & 0.2 & 117 & 10.7 & 13.6 & 16.3 & 2.5 & 15.0 & 0.2 & 200 & 11.9 & 15.0 & 17.3 \\
\hline $14.0-14.9$ & 1.5 & 13.4 & 0.2 & 264 & 10.5 & 13.4 & 16.0 & 2.5 & 15.0 & 0.2 & 275 & 11.9 & 15.0 & 17.4 \\
\hline $15.0-15.9$ & 1.4 & 13.1 & 0.2 & 202 & 10.2 & 13.1 & 15.8 & 2.4 & 15.0 & 0.2 & 208 & 11.9 & 15.0 & 17.4 \\
\hline $16.0-16.9$ & 1.2 & 12.7 & 0.2 & 187 & 9.9 & 12.7 & 15.4 & 2.4 & 15.0 & 0.2 & 264 & 11.9 & 15.0 & 17.4 \\
\hline $17.0-17.9$ & 1.0 & 12.4 & 0.2 & 241 & 9.7 & 12.4 & 15.1 & 2.5 & 15.0 & 0.2 & 352 & 12.0 & 15.0 & 17.4 \\
\hline 18.0-18.9 & 0.7 & 12.3 & 0.2 & 80 & 9.7 & 12.3 & 15.0 & 2.5 & 15.1 & 0.2 & 156 & 12.1 & 15.1 & 17.4 \\
\hline \multicolumn{15}{|c|}{ Motor dimension } \\
\hline 11.0-11.9 & 1.2 & 12.6 & 0.2 & 82 & 9.7 & 12.6 & 15.2 & 1.9 & 13.4 & 0.2 & 95 & 10.8 & 13.4 & 15.7 \\
\hline $12.0-12.9$ & 1.3 & 12.3 & 0.2 & 185 & 9.4 & 12.3 & 15.1 & 1.5 & 13.4 & 0.2 & 152 & 10.7 & 13.4 & 15.8 \\
\hline 13.0-13.9 & 1.4 & 12.1 & 0.2 & 117 & 9.0 & 12.1 & 14.8 & 1.3 & 13.2 & 0.2 & 200 & 10.5 & 13.2 & 15.8 \\
\hline $14.0-14.9$ & 1.3 & 11.9 & 0.2 & 264 & 8.9 & 11.9 & 14.7 & 1.1 & 13.1 & 0.2 & 275 & 10.4 & 13.1 & 15.8 \\
\hline $15.0-15.9$ & 1.2 & 11.6 & 0.2 & 202 & 8.8 & 11.6 & 14.4 & 1.0 & 13.2 & 0.2 & 208 & 10.3 & 13.2 & 16.0 \\
\hline $16.0-16.9$ & 1.1 & 11.2 & 0.2 & 187 & 8.5 & 11.2 & 13.8 & 1.0 & 13.1 & 0.2 & 264 & 10.3 & 13.1 & 16.0 \\
\hline $17.0-17.9$ & 1.0 & 11.0 & 0.2 & 241 & 8.5 & 11.0 & 13.6 & 1.0 & 13.1 & 0.2 & 352 & 10.3 & 13.1 & 16.0 \\
\hline 18.0-18.9 & 0.8 & 11.1 & 0.2 & 80 & 8.7 & 11.1 & 13.6 & 1.0 & 13.3 & 0.2 & 156 & 10.4 & 13.3 & 16.2 \\
\hline \multicolumn{15}{|c|}{ Cardiovascular dimension } \\
\hline $11.0-11.9$ & 2.0 & 10.1 & 0.2 & 82 & 8.1 & 10.1 & 11.7 & 2.7 & 10.5 & 0.2 & 95 & 8.6 & 10.5 & 11.9 \\
\hline $12.0-12.9$ & 2.0 & 10.0 & 0.2 & 185 & 7.9 & 10.0 & 11.7 & 2.5 & 10.5 & 0.2 & 152 & 8.6 & 10.5 & 12.0 \\
\hline $13.0-13.9$ & 2.0 & 9.9 & 0.2 & 117 & 7.8 & 9.9 & 11.7 & 2.4 & 10.6 & 0.2 & 200 & 8.6 & 10.6 & 12.1 \\
\hline $14.0-14.9$ & 1.9 & 9.8 & 0.2 & 264 & 7.7 & 9.8 & 11.6 & 2.3 & 10.5 & 0.2 & 275 & 8.6 & 10.5 & 12.1 \\
\hline $15.0-15.9$ & 1.9 & 9.6 & 0.2 & 202 & 7.6 & 9.6 & 11.4 & 2.3 & 10.5 & 0.2 & 208 & 8.5 & 10.5 & 12.1 \\
\hline $16.0-16.9$ & 1.8 & 9.5 & 0.2 & 187 & 7.4 & 9.5 & 11.2 & 2.3 & 10.5 & 0.2 & 264 & 8.5 & 10.5 & 12.1 \\
\hline $17.0-17.9$ & 1.8 & 9.4 & 0.2 & 241 & 7.3 & 9.4 & 11.1 & 2.3 & 10.5 & 0.2 & 352 & 8.4 & 10.5 & 12.1 \\
\hline 18.0-18.9 & 1.7 & 9.3 & 0.2 & 80 & 7.2 & 9.3 & 11.0 & 2.3 & 10.5 & 0.2 & 156 & 8.4 & 10.5 & 12.2 \\
\hline \multicolumn{15}{|c|}{ EAPAF (total) } \\
\hline $11.0-11.9$ & 2.4 & 43.7 & 0.1 & 82 & 37.0 & 43.7 & 49.3 & 3.1 & 53.0 & 0.1 & 95 & 44.9 & 53.0 & 59.1 \\
\hline $12.0-12.9$ & 2.1 & 43.0 & 0.1 & 185 & 36.1 & 43.0 & 48.8 & 2.9 & 53.3 & 0.1 & 152 & 45.3 & 53.3 & 59.5 \\
\hline $13.0-13.9$ & 1.8 & 42.3 & 0.2 & 117 & 35.3 & 42.3 & 48.4 & 2.9 & 53.0 & 0.1 & 200 & 45.1 & 53.0 & 59.2 \\
\hline $14.0-14.9$ & 1.5 & 41.8 & 0.2 & 264 & 34.9 & 41.8 & 48.1 & 3.0 & 52.9 & 0.1 & 275 & 44.9 & 52.9 & 59.1 \\
\hline $15.0-15.9$ & 1.3 & 41.0 & 0.2 & 202 & 34.3 & 41.0 & 47.4 & 3.0 & 52.9 & 0.1 & 208 & 44.9 & 52.9 & 59.1 \\
\hline $16.0-16.9$ & 1.2 & 39.9 & 0.2 & 187 & 33.4 & 39.9 & 46.2 & 3.1 & 52.8 & 0.1 & 264 & 44.8 & 52.8 & 58.8 \\
\hline $17.0-17.9$ & 1.0 & 39.3 & 0.2 & 241 & 33.0 & 39.3 & 45.6 & 3.2 & 52.9 & 0.1 & 352 & 44.9 & 52.9 & 58.9 \\
\hline 18.0-18.9 & 0.8 & 39.0 & 0.2 & 80 & 32.9 & 39.0 & 45.3 & 3.3 & 53.4 & 0.1 & 156 & 45.4 & 53.4 & 59.3 \\
\hline
\end{tabular}

$\mathrm{L}=$ asymmetry; $\mathrm{M}=$ median; $\mathrm{S}=$ variation coefficient; $\mathrm{EAPAF}=$ self-perception of physical fitness scale. 

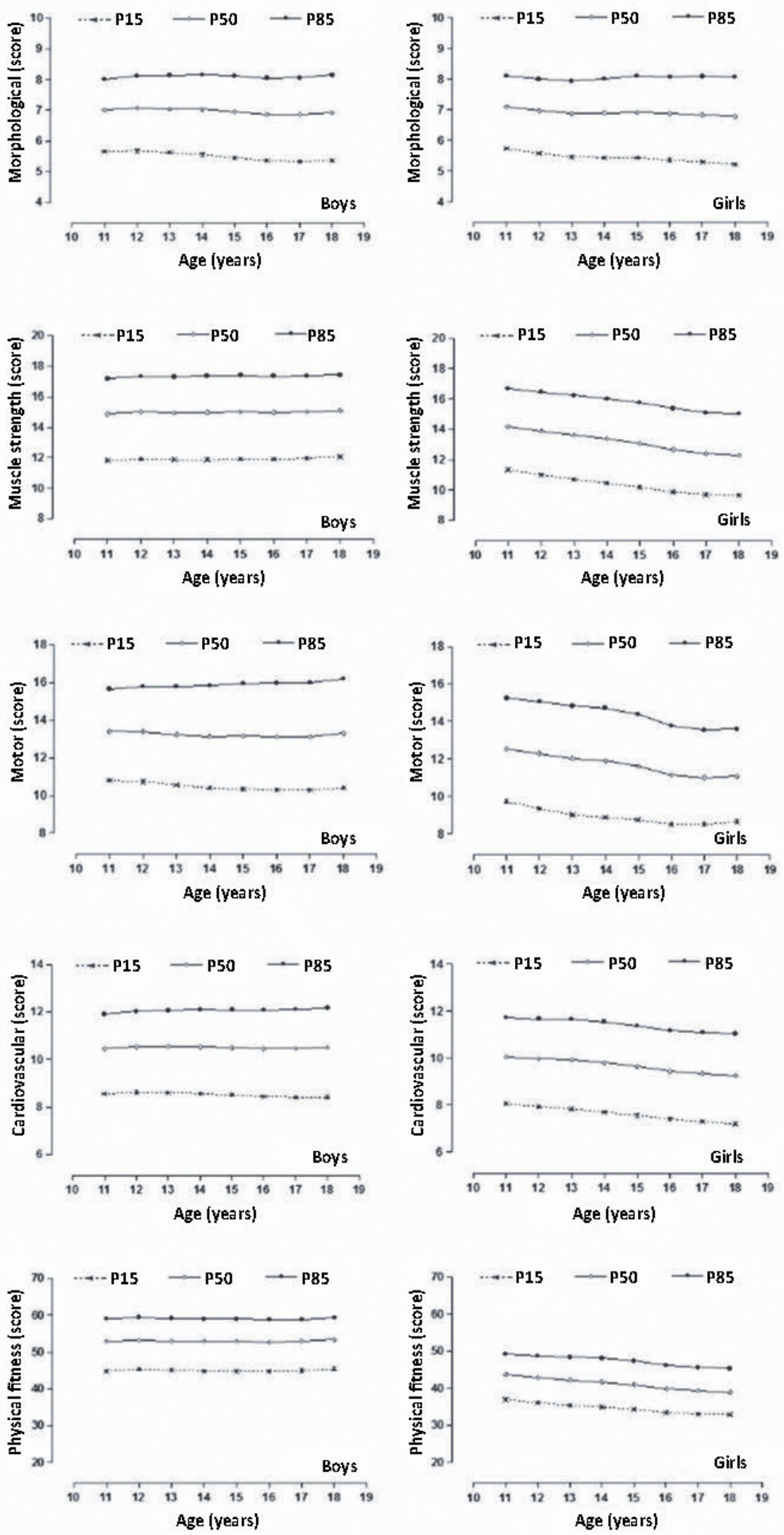
develop instrument validation.

In this regard, following the field test, a confirmatory factor analysis (CFA) was developed to validate the scale. During this process, the four domains initially proposed were confirmed.

These results evidenced saturation values above 0.4016 and eigenvalues far above $1.0 .{ }^{17} \mathrm{Six}$ questions had been previously removed due to saturation values below 0.39 , which resulted in an improved percentage of explained variance for the entire instrument of $54.24 \%$.

Basically, and although there are no instruments available to study the validity of selfperception of physical fitness among adolescents using a CFA, the results of this study are similar to those obtained in other studies that assessed physical fitness ${ }^{18}$ and similar objectives. ${ }^{19}$ In general, studies using CFA seek to contrast substantial theories, ${ }^{16}$ which is evidently reflected in the homogeneity of each of its factors and the corresponding items (questions), as determined in this study.

To establish the EAPAF reliability in this study, an internal consistency analysis was performed. Reliability acceptable values range from 0.70 to $0.90 .{ }^{20}$ The overall scale showed a Cronbach's alpha of 0.84 , which evidences a high reproducibility. This value was observed consistently in other similar studies, ${ }^{8}$ given that this is the most widely used coefficient, preferred for studies implementing survey techniques, ${ }^{21}$ especially because it is closely related to saturations reported during the CFA process. ${ }^{22}$

It is worth noting that reliability estimations change when the instrument is applied to different populations, so it is necessary to check certain factors that may reduce the reliability coefficient, e.g., item difficulty and instrument length. ${ }^{23}$

In this regard, the scale was developed using simple language, easily understood by adolescents and, considering the number of items (18 questions), could be completed in a reasonable time (10-15 minutes). Therefore, given its characteristics, the EAPAF poses no difficulties in relation to its questions and length, and it is unlikely to make adolescents completing it bored or tired.

In relation to the proposal for standards, the study used the LMS method to establish percentiles by dimension, age and sex. This type of instrument usually helps to classify and/or diagnose an individual's or a population's health status. ${ }^{24}$ Previous studies have even used this technique to develop references in relation to physical fitness among children and adolescents from a quantitative perspective. ${ }^{25.26}$

The standards proposed here may be an alternative for follow-up and surveillance of selfperception of physical fitness among adolescents. This is relevant as long as it is used in health care and enables the fast detection of a problem, especially within epidemiological contexts where lack of time, sophisticated equipment use and restricted availability of qualified personnel hinder the possibility of assessing physical fitness in an objective manner.

In this study, the EAPAF is classified into three categories $(<$ p15: low, $\geq$ p15 to p85: moderate, and > p15: high perception); therefore, in terms of population health, the lowest percentiles may be used as a warning sign given that low physical fitness levels during childhood are associated with a greater risk for cardiovascular disease during adulthood. ${ }^{26}$ On the contrary, subjects with higher physical fitness levels are associated with a better health status, and this obviously implies doing more physical activity which, as a result, may help to achieve cognitive performance and prevent disease at the level of society. ${ }^{27}$

Therefore, using this reference at schools is an urgent need in Chile, where a high percentage of

TABLE 4. Comparison of average values and \pm standard deviation of the self-perception of physical fitness scale based on sex

\begin{tabular}{lcccccc}
\hline Dimensions & \multicolumn{2}{c}{ Girls $(\mathbf{n}=\mathbf{1 3 5 8})$} & \multicolumn{2}{c}{ Boys $(\mathbf{n = 1 7 0 2})$} & \multicolumn{2}{c}{ Both $(\mathbf{n}=\mathbf{3 0 6 0})$} \\
& $\mathbf{X}$ & $\mathbf{S D}$ & $\mathbf{X}$ & $\mathbf{S D}$ & $\mathbf{X}$ & $\mathbf{S D}$ \\
\hline Morphological & 6.70 & 1.44 & 6.78 & 1.40 & 6.75 & 1.47 \\
Muscle strength & 12.99 & 2.84 & 14.62 & $2.90^{*}$ & 13.91 & 2.98 \\
Motor & 11.58 & 2.70 & 13.16 & $2.70^{*}$ & 12.44 & 2.86 \\
Cardiovascular & 9.46 & 2.02 & 10.27 & $1.90^{*}$ & 9.91 & 1.99 \\
Level of physical fitness & 40.74 & 6.78 & 44.87 & $6.72^{*}$ & 43.02 & 7.05 \\
\hline
\end{tabular}

* Significant difference $(\mathrm{p}<0.001)$ compared to girls. SD: standard deviation. 
adolescents have been observed to have physical activity and fitness levels below those included in recommendations..$^{28}$ In this regard, Physical Education teachers and/or coaches at schools could use percentiles as a basic tool to identify adolescents who have a low self-perception of physical fitness. Consequently, physical activity should be promoted and encouraged to improve physical performance levels among students.

In addition, the comparison between boys and girls showed no differences in the morphological dimension. Mean values were similar. However, in the other dimensions (muscle strength, motor and cardiovascular), boys obtained a higher score than girls.

Clearly, some recent studies reinforce these findings: it has been verified that men do more physical activity than women. ${ }^{21,29,30}$ Such differences may be based on the presence of social determinants that, in general, appear during the critical adolescent stage. ${ }^{31}$ Therefore, factors such as peer and family influence and the type of physical activity program established for each sex may play a significant role in the differences between men and women.

It is necessary to mention some of the limitations of this study. For example, no quantitative assessments of adolescent physical fitness were done, so the instrument lacks crossvalidation; besides, data used to develop the references were obtained only from the Maule Region (Chile).

For future studies, we recommend using the EAPAF in other South American countries and Chilean regions, and to implement it in other samples different than the one used here. This study's main purpose is to achieve external validation and, as a result, the possibility of using it globally.

It is also worth noting some of the study's strengths. Given that this study was conducted in a small, representative sample of adolescents, the instrument we developed met quality control filters (validity and reliability) and its use and implementation may be useful and relevant from a subjective perspective to assess physical fitness among adolescents.

Estimations may be done in the following web site: http://reidebihu.net/cuesaptfisch.php.

\section{CONCLUSION}

The instrument developed in this study is valid and reliable. In addition, the reference proposed is a useful tool to classify adolescents in relation to their self-perception of physical fitness in the 11.0-18.9 year-old group. Findings suggest that the scale could be used and implemented to monitor physical fitness in situations where it cannot be measured objectively in both the health and education settings.

\section{REFERENCES}

1. Pangrazi RP, Hastad DN. Fitness in the elementary schools. 2nd ed. Reston: American Alliance for Health, Physical Education, Recreation and Dance; 1989.

2. Ortega FB, RuizJR, Castillo MJ, Sjöström M. Physical fitness in childhood and adolescence: a powerful marker of health. Int J Obes (Lond) 2008;32(1):1-11.

3. Clarke HH. Basic understanding of physical fitness. Pres Counc Phys Fit Sports Res Dig 1971;1(1).

4. Cveji D, Pejovi T, Ostoji S. Assessment of physical fitness in children and adolescents. Physical Education and Sport 2013;11(2):135-45.

5. American Alliance for Health, Physical Education, and Recreation. Youth Fitness Test Manual. Revised edition. Washington DC: AAHPER; 1975.

6. Council of Europe. Testing physical fitness EUROFIT experimental battery: provisional handbook. Strasbourg: Council of Europe; 1983.

7. Ortega FB,Sánchez-LópezM,Solera-MartínezM,FernándezSánchezA, et.al.Self-reported and measured cardiorespiratory fitness similarly predict cardiovascular disease risk in young adults. Scand J Med Sci Sports 2013;23(6):749-57.

8. Gómez Campos R, De Arruda M, Camargo C, CossioBolaños MA. Confiabilidad de un cuestionario que valora la actividad física en adolescentes normopeso y con exceso de peso. Nutr Hosp 2015;31(5):2205-11.

9. Chile. Agencia de Calidad de la Educación. Informe de Resultados SIMCE Educación Física 8. ${ }^{\circ}$ Básico 2012 para Docentes y Directivos. Santiago de Chile: Agencia de Calidad de la Educación; 2012. [Accessed on: January 18, 2016]. Available at: http://www.agenciaeducacion.cl/ wp-content/uploads/2013/08/WEB_IR_8_basico_Ed_ Fisica_2012.pdf.

10. Castro-Piñero J, Artero EG, España-Romero V, Ortega FB, et al. Criterion related validity of field-based fitness tests in youth: A systematic review. Br J Sports Med 2010;44(13): 934-43.

11. Cole TJ, Bellizzi MC, Flegal KM, Dietz WH. Establishing a standard definition for child overweight and obesity worldwide: international survey. BMJ 2000;320(7244):1240-3.

12. Marsh HW. Physical fitness self-concept: relations of physical fitness to field and technical indicators in boys and girls aged 9-15. J Sport Exerc Psychol 1993;15(2):184-206.

13. Jürimäe T, Saar M. Self-perceived and actual indicators of motor abilities in children and adolescents. Percept Mot Skills 2003;97(3 Pt 1):862-6.

14. SchmittFF. Truth: A primer. Boulder: Westview Press;1995.

15. PetteeKK,MorrowJRJr, Woolsey AL:Frameworkforphysical activity as a complex and multidimensional behavior.J Phys Act Health 2012;9(Suppl 1):S11-8.

16. Batista-Foguet JM, Coenders G, Alonso J. Análisis factorial confirmatorio. Su utilidad en la validación de cuestionarios relacionados con la salud. Med Clin (Barc) 2004;122(Supl 1):21-7.

17. Kaiser HF. The application of electronic computers to factor analysis. Educ Psychol Meas 1960;20(1):141-51.18.

18. Ryckman RM, Robbins MA, Thornton B, Cantrell P. Development and validation of a physical self-efficacy scale. J Pers Soc Psychol 1982;42(5):891-900. 
19. Pino JL, Díaz C, López MA. Construcción y validación de un cuestionario para medir conductas y hábitos alimentarios en usuarios de la atención primaria de salud. Rev Chil Nutr 2011;38(1):41-51.

20. Oviedo HC, Campo-Arias A. Aproximación al uso del coeficiente alfa de Cronbach. Rev Colomb Psiquiatr 2005;34(4):572-80

21. Cossio-Bolaños MA, Viveros-Flores A, Castillo-Retamal M, Vargas-Vitoria R, et al. Patrones de actividad física en adolescentes en función del sexo, edad cronológica y biológica. Nutr Clin Diet Hosp 2015;35(2):41-7.

22. Cortina JM. What is coefficient alpha? An examination of theory and applications. J Appl Psychol 1993;78(1):98-104.

23. Gregory RJ. Psychological testing: history, principles and applications. Boston: Allyn and Bacon: 1992.

24. Conde W, Monteiro CA. Body mass index cutoff points for evaluation of nutritional status in Brazilian children and adolescents. J Pediatr (Rio J) 2006;82(4):266-72.

25. Ortega FB, RuizJR, Castillo MJ, Moreno LA, et al. Bajo nivel de forma física en los adolescentes españoles. Importancia para la salud cardiovascular futura (Estudio AVENA). Rev Esp Cardiol 2005;58(8):898-909.
26. Santos R, MotaJ,Santos DA, Silva AM, et.al. Physical fitness percentiles for Portuguese children and adolescents aged 10-18 years. J Sports Sci 2014;32(16):1510-8.

27. Åberga MA, Pedersen NL, Torén K, Svartengren M, et al. Cardiovascular fitness is associated with cognition in young adulthood. Proc Natl Acad U S A 2009;106(49):20906-11.

28. Garber MD, Sajuria M, Lobelo F. Geographical Variation in Health-Related Physical Fitness and Body Composition among Chilean 8th Graders: A Nationally Representative Cross-Sectional Study. PloS One 2014;9(9):e108053.

29. Biddle SJH, Gorely T, Stensel DJ. Health-enhancing physical activity and sedentary behaviour in children and adolescents. J Sports Sci 2004;22(8):679-701.

30. TrostSG, Rosenkrantz RR, DzewaltowskiD. Physical activity levels among children attending after school programs. Med Sci Sports Exerc 2008;40(4):622-9.

31. PateRR, DowdaM, O'NeillJR, WardDS. Change in physical activity participation among adolescent girls from 8th to 12th grade. J Phys Act Health 2007;4(1):3-16. 
ANNEX

\section{QUESTIONNAIRE ON SELF-PERCEPTION OF PHYSICAL FITNESS}

Name:

Date of birth: (day) / (month) / (year). Sex: M / F. Geographic area of residence: urban/rural. Parents' qualifications: professional / technical / trade. Do you do any sport at school?: yes / sometimes / never. Do you do any physical activity outside school?:

Do you smoke?: always/sometimes/never.

Mark the answer with an X. You can only mark one option.

1. In general, my weight is within normal ranges for my age and sex.

\begin{tabular}{|c|c|c|}
\hline SA (3) & NAND (2) & $\mathrm{SD}(1)$ \\
\hline SA (3) & NAND (2) & SD (1) \\
\hline EW (3) & Normal (2) & LW (1) \\
\hline SA (3) & NAND (2) & SD (1) \\
\hline SA (3) & NAND (2) & SD (1) \\
\hline SA (3) & NAND (2) & $\mathrm{SD}(1)$ \\
\hline SA (3) & NAND (2) & $\mathrm{SD}(1)$ \\
\hline SA (3) & NAND (2) & $\mathrm{SD}(1)$ \\
\hline Good (3) & Acceptable (2) & Poor (1) \\
\hline SA (3) & NAND (2) & $\mathrm{SD}(1)$ \\
\hline SA (3) & NAND (2) & $\mathrm{SD}(1)$ \\
\hline SA (3) & NAND (2) & $\mathrm{SD}(1)$ \\
\hline SA (3) & NAND (2) & $\mathrm{SD}(1)$ \\
\hline Good (3) & Acceptable (2) & Poor (1) \\
\hline SA (3) & NAND (2) & $\mathrm{SD}(1)$ \\
\hline SA (3) & NAND (2) & $\mathrm{SD}(1)$ \\
\hline SA (3) & NAND (2) & $\mathrm{SD}(1)$ \\
\hline Good (3) & Acceptable (2) & Poor (1) \\
\hline
\end{tabular}

2. Often during the development stage, my height is within normal ranges for my age and sex.

3. In general, based on my present nutritional status, I think I belong to the following nutritional status category:

4. I can usually hang off a bar for 10 seconds or more.

5. In general, I like doing abs.

6. I feel I can easily do push-ups, at least, 5 push-ups.

7. I often easily leap over an obstacle (one-foot takeoff to a landing on the other foot), either while walking or jogging.

8. I can pull myself up to the bar (hang from the bar) several times.

9. Level of muscle strength for my age and sex:

10. I often quickly and easily catch a ball with both hands.

11. In general, I can run at top speed more than 30 meters in a straight line.

12. Given my present physical characteristics, I can run 4 meters at top speed (back and forth more than 6 times).

13. I can easily run and leap over obstacles on a straight line (without knocking down the obstacles).

14. Level of agility for my age and sex:

15. I can walk up six flights of stairs without stopping.

16. I can easily jog for more than 15 minutes continuously and without stopping.

17. I can frequently hold my breath for at least 30 seconds.

Good (3) Acceptable (2) Poor (1)

18. General consideration of my cardiorespiratory fitness:

SA: strongly agree; NAND: neither agree nor disagree; SD: strongly disagree; EW: excess weight; NW: normal weight; LW: low weight. 